\title{
Optimizing the Management of the Occupational Safety and Health System in "ArcelorMittal" Prijedor on the Basis of Performance Indicators
}

\author{
Biljana VRANJEŠ, Mladen TODIĆ, Valentina GOLUBOVIĆ-BUGARSKI
}

\begin{abstract}
New hazards and risks that arise as a consequence of the development of technologies and business processes require new standardized methods for managing the occupational safety and health system, one of them performance indicators. Defining the performance indicators is an effective way of monitoring the functioning of the occupational safety system and assessing its quality. Modern understanding of occupational safety implies active engagement of all stakeholders, with a particularly prominent participation of workers in the creation and improvement of the occupational safety system. Using the survey questionnaire as a research instrument, the state of occupational safety in the mining production system was scanned. The research is based on the application of a simple model of perception analysis and worker's attitudes in regard to the way the occupational safety and health system functions and performance indicators. The aim of the research is through the active involvement of workers find out which elements of the occupational health and safety system do not meet their demands. The research should determine whether and to what extent there is a correlation between the established occupational health and safety system in the observed production system and the results of its functioning in the form of performance and injuries at work indicators. The results of the analysis can be the basis for defining improvement measures in the occupational safety system, learning about organizational and functional advantages and disadvantages in the occupational safety process, and then acting in order to eliminate defects. The correlation established by the analysis indicates that the improvement of certain elements of the occupational health and safety system can also affect its performance. The model shown should be used in the process of optimizing the occupational health and safety system in production systems to create measures in order to improve the existing system and to obtain the best possible indicators, obvious being injuries at work indicators.
\end{abstract}

Keywords: occupational safety and health; performance indicators; workers

\section{INTRODUCTION}

Managing an occupational safety system implies a specific organizational structure that combines responsibilities, procedures, processes, resources, and information to perform occupational safety activities [1]. Basic models of the organizational structure of occupational safety management are as follows:

- vertical or linear management approach,

- horizontal or process management approach and

combined or life cycle management approach [1, 2].

The model presenting the occupational safety system under study and its established process activities is shown in Fig. 1.

Key Performance Indicators (KPIs) define a set of values that are used to measure the performance or results of an activity or a process. In occupational safety they are used to measure progress towards certain safety and health objectives or to monitor trends related to the activities of a business organization or specific projects [3].

Numerical indicators of occupational safety should provide information to the company management on what the current problems and difficulties are in providing occupational safety and health [4]. At present, the real state of occupational safety and health in the company requires that it creates corrective measures for the resulting changes if necessary. The improvement of each system, and also the occupational safety and health system, is based on getting feedback, but it is only a prerequisite, not a guarantee of successful occupational safety management [5]. Application of modern information technologies enables complex and comprehensive analysis of collected data and evaluation of the effectiveness of applied occupational safety measures as well as improvement of the decisionmaking process related to improvement of applied and selection of new measures in the management of occupational safety processes in mines [5]. The function of the occupational safety and health system should be to achieve safe working conditions by preventing and eliminating hazards and harmfulness that can cause injuries at work and other forms of disruption to worker's health. Injuries are the main cause of death and disability at the workplace [6]. Basic indicators of the state of working environment, i.e. the efficiency and quality of the occupational safety system, are the number of injuries, occupational diseases, work-related illnesses, parameters of professional traumatism. Quality is the desired outcome of a system's functioning, and the quality of the occupational safety system is shown by injury indicators. Occupational safety and health indicators do not have to be directly related to the consequences due to poor functioning of the occupational safety (a greater number of injuries and occupational diseases), but they can provide useful information for improvements such as:

- financial investments of the organization in the occupational safety,

- employee's perception of the management's commitment towards occupational safety,

- the assessment of training and education in occupational safety,

- employee's participation in addressing occupational safety issues,

- a culture of dialogue between the management and its employees on occupational safety issues, etc.

The system of occupational safety established in the company and the way in which it operates in achieving the occupational safety objectives directly affects the performance indicators. A long-term goal occupational safety in the company under study, as it should be in every production system, is that there are no injuries with fatal outcome or lost time (sick leave).

The Occupational Safety and Health Program called "Zero accidents vision" (ZAV) is designed to achieve this goal. ZAV is both the ambition and definition to creating and ensuring safe and healthy work and to preventing all 
accidents in order to achieve safety [7]. Historically, there has been a tendency within the mining industry to focus more attention on the development, use and reporting of safety indicators than on occupational safety and health [8]. Safety and health leading indicators are necessary to ensure the total wellbeing of employees in the mining industry, and prevention of accident is a core driver of management approaches to occupational safety. The study [9] analyzes safety and health systems of 26 mining companies to determine the quantity of safety and health practices which encourage the use of indicators when checking and acting in order to manage safety and health performance.

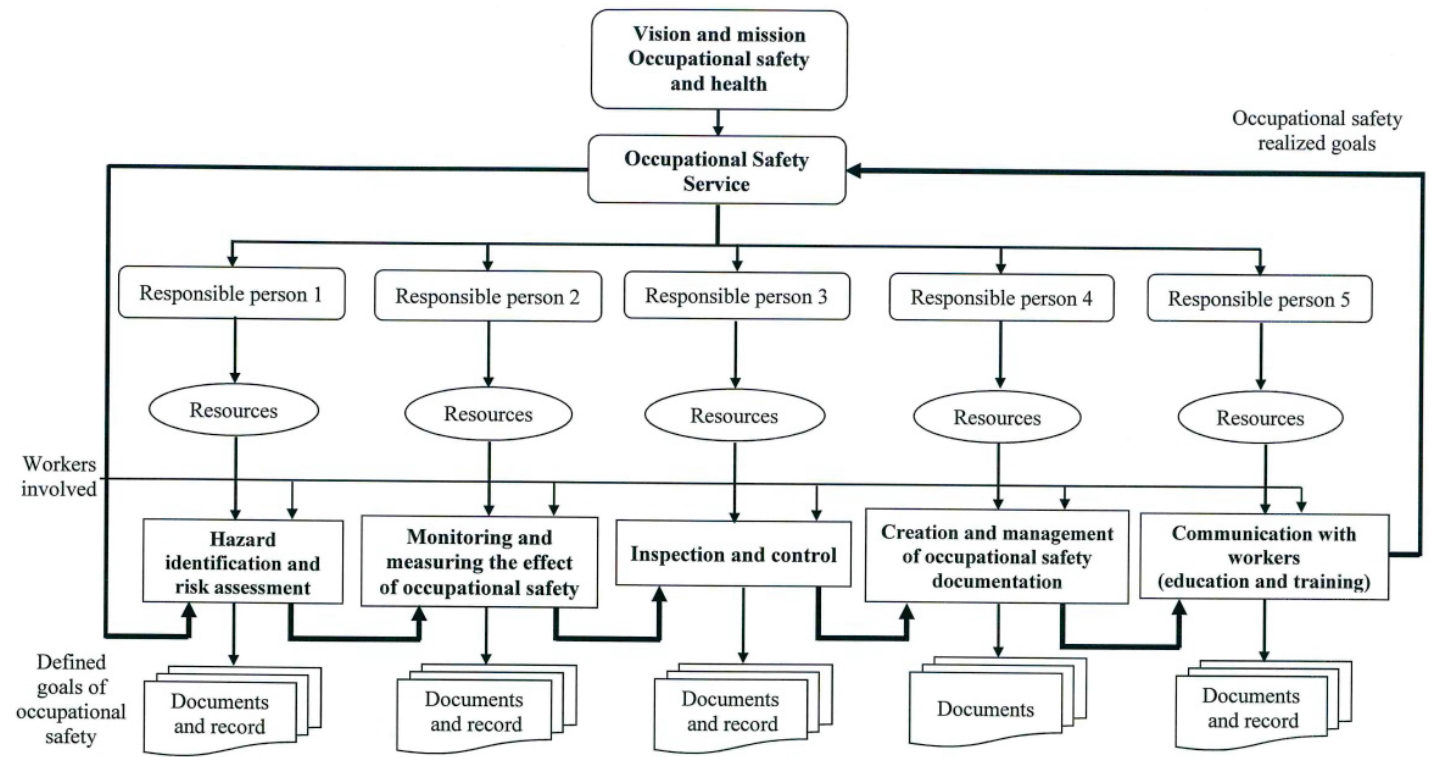

Figure 1 Model of occupational safety system in the observed production system "ArcelorMittal" Prijedor [1]

There are various approaches to occupational safety in mines around the world [10-12], and in regard the calculation and monitoring of injury indicators at work [13]. The effects of occupational safety in the production system "ArcelorMittal" Prijedor are measured by the following two main indicators, for which the data are shown in Tab. 1, and the values obtained in Figs. 2 and 3:

- $\quad$ injury frequency rate with lost time $(F r)[14]$

Fr $=\frac{\text { Number of injuries with lost time }}{\text { Number of working hours }} \cdot 10^{6}$

- $\quad$ injury severity rate with lost time $(S r)[15]$

$S r=\frac{\text { Number of lost working day }}{\text { Number of working hours }} \cdot 10^{3}$

Table 1 Data for the calculation of injury indicators (frequency and severity rate) in "ArcelorMittal" Prijedor for the 2009-2018 period

\begin{tabular}{|c|c|c|c|}
\hline Year & $\begin{array}{c}\text { Number of injuries } \\
\text { with lost time }\end{array}$ & $\begin{array}{c}\text { Number of lost } \\
\text { working days }\end{array}$ & $\begin{array}{c}\text { Number of } \\
\text { working hours }\end{array}$ \\
\hline 2009 & 5 & 239 & 1171361 \\
\hline 2010 & 3 & 331 & 1320590 \\
\hline 2011 & 5 & 216 & 1541360 \\
\hline 2012 & 1 & 127 & 1565904 \\
\hline 2013 & 0 & 0 & 1569103 \\
\hline 2014 & 0 & 0 & 1568943 \\
\hline 2015 & 1 & 89 & 1555526 \\
\hline 2016 & 1 & 308 & 1368091 \\
\hline 2017 & 1 & 263 & 1364028 \\
\hline 2018 & 7 & 470 & 1364480 \\
\hline
\end{tabular}

The data presented in Tab. 1 indicate that the occupational safety situation should be constantly monitored since the goal of "zero injuries" achieved in a certain period did not persist, as there was an increase in the number of injuries and indicators of the state of occupational safety last year.

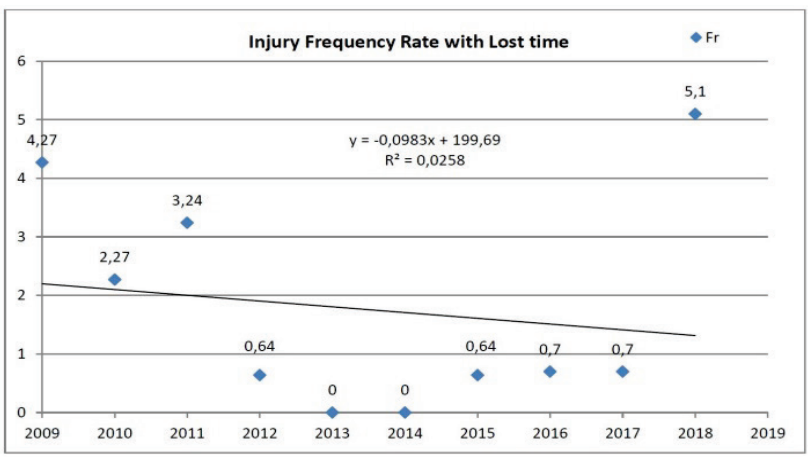

Figure 2 The injury frequency rate with lost time in "ArcelorMittal" Prijedor for the 2009-2018 period

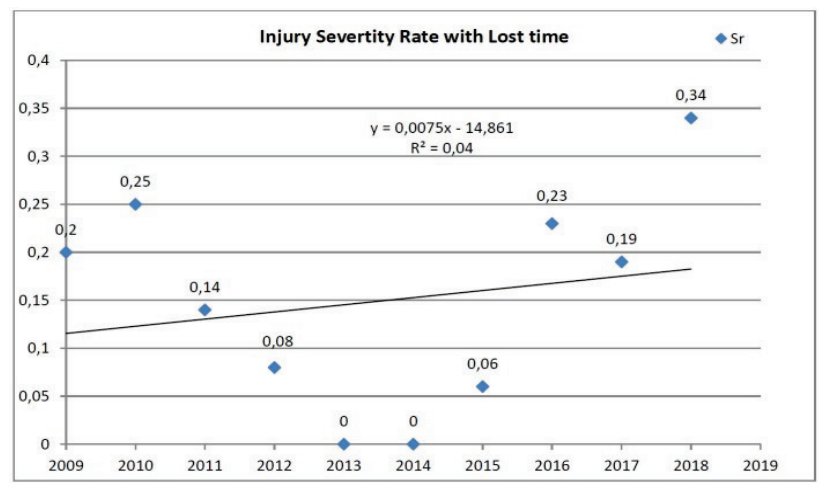

Figure 3 The injury severity rate with lost time in "ArcelorMittal" Prijedor for the 2009-2018 period 
The calculated value of the injury frequency rate in Fig. 2 is shown by the decreasing linear trend model $(b=-$ 0,0983 ), and the value of the severity gradient by the increasing linear trend model $(b=0,0075)$ in Fig. 3. Tolerant values for the injury frequency with lost time include the numbers between 5 and 10 injuries for every $10^{6}$ working hours and for a severity of 0,5 to 1 for $10^{3}$ working hours [16]. The fact that there is stability established and that these indicators are kept within tolerant limits shows that additional measures of optimization of the existing occupational safety and health model in the production system are not currently required.

There is an overall consensus in research that occupational safety and health management should be seen as part of the overall business management structure, fostering a culture of continuous improvement, and worker's involvement has a positive effect on occupational safety and health performance [17]. To make a workplace safe, the management has to know what employees are thinking. Organization can use a survey with an analysis of workers' attitudes in order to develop positive safety perceptions and to find solutions to safety problems and a world-class safety system is achievable [18].

\section{MATERIAL AND METHODS}

The aim of the research is to determine a degree of system integration and the performance of the occupational safety and health system in the production system and its importance in relation with the management potential. The initial hypothesis of this research is that there is a connection between the established occupational safety system in the production system and indicators/ performance in regard of injuries indicators and other indicators of occupational safety and health.

Worker's subjective opinions (specific and experienced) were the source of information for determining the state of the occupational health and safety system using the method of a representative sample by the survey. As potential respondents in the research were workers in the production system "ArcelorMittal" Prijedor, i.e. about 800 potential respondents. "ArcelorMittal" Prijedor d.o.o. is an iron ore mine located in the northwest of Bosnia and Herzegovina. At the moment, they are working on the open pit Buvač. The main activity is the production of iron ore and the auxiliary activities are the production of stone aggregates, machine and electrical maintenance and transport services. The survey was implemented in 2018 and the survey sheets were validly filled in by 300 workers.

A written descriptive-analytical questionnaire was used as a research instrument, which was filled in by workers-respondents in the researcher's presence. The survey was conducted voluntarily and anonymously. Survey questions were grouped into four (4) groups based on independent and dependent variables:

1. Independent variables [4]: Worker's profile and The occupational safety and health system in the organization

2. Dependent variables: Injuries at work in the organization and The state (performance) of occupational safety and health in the organization $[1,4]$

Those questions are closed type with offered answers, one of which can be selected. The workers' subjective opinions about the questions and their assessment were given according to the Likert scale of the intensity of 5 (min. value 1, max. value 5) and 3 (min. value 1, max. value 3) responses offered [19].

Except statistical analysis with standard statistical indicators ( $N$ - frequency, $\%$ - percentage, $M$ - arithmetic mean and standard deviation), the following were used: verification of distribution normality and nonparametric statistics methods Kolmogorov - Smirnov test, coefficient of correlation (Spearman rho) and correlation matrix. Statistical data processing was performed in the IBM SPSS Statistics 23 software package.

\section{RESULTS AND DISCUSSION}

Structure of the research sample (dominant percentage value) in relation to the independent variable Worker's profile is: workers-respondents were men $(81.7 \%)$, aged 51 to $60(36.3 \%)$, with a high school degree $(76 \%)$ and over 30 years of total work experience $(38 \%)$.

According to the results of descriptive statistics for 28 individual variables of the scale of The occupational safety and health system in the organization, the arithmetic mean is 4.09 and the standard deviation is 0.929 . The value of the arithmetic mean above four indicates worker's satisfaction with the achieved degree of occupational safety and health in the research company. Such high rating by the workers must not stop the process of continuous monitoring and improvement, as it is an open system subject to the constant impact of internal and external factors that may affect its effectiveness.

Table 2 Deviation of distribution of results from normal distribution within the selected research variables

\begin{tabular}{|c|c|c|c|c|c|c|}
\hline \multicolumn{7}{|c|}{ Tests of Normality } \\
\hline \multirow{2}{*}{ Production system } & \multicolumn{3}{|c|}{ Kolmogorov-Smirnov $^{\mathrm{a}}$} & \multicolumn{3}{|c|}{ Shapiro-Wilk } \\
\hline & Statistic & $d f$ & Sig. & Statistic & $d f$ & Sig. \\
\hline The occupational safety and health system in the organization [1] & 0,127 & 300 & 0,000 & 0,910 & 300 & 0,000 \\
\hline Injuries at work in the organization & 0,075 & 300 & 0,000 & 0,982 & 300 & 0,001 \\
\hline The state (performance) of occupational safety and health in the organization [1] & 0,153 & 300 & 0,000 & 0,968 & 300 & 0,000 \\
\hline
\end{tabular}

Many statistical techniques are based on the assumption about normal distribution of variables, before further data processing, normality check was performed. Kolmogorov-Smirnov's normality test of variance was used to verify normal distribution of variables (Tab. 2). The results presented in Tab. 2 obtained by the Kolmogorov-
Smirnov test show the degree of deviation of the obtained results from normal distribution within individual scales of independent and dependent variables at the significance level $p<0,01$.

On the basis of these results of deviation from normality it is necessary to transform the research variables 
(adjustment to the normal distribution), thus nonparametric statistics will be used in further statistical analysis. Results of descriptive statistics of transformed variables for the whole sample are shown in Tab. 3.

Table 3 Results of descriptive statistics for transformed research variables

\begin{tabular}{|c|c|c|c|c|}
\hline \multicolumn{5}{|c|}{ Descriptive Statistics } \\
\hline Production system & Min. & Max. & Mean & Std. Deviation \\
\hline The occupational safety and health system in the organization [1] & 43 & 140 & 114,42 & 17,053 \\
\hline Injuries at work in the organization & 10 & 40 & 27,25 & 5,135 \\
\hline The state (performance) of occupational safety and health in the organization [1] & 8 & 24 & 16,36 & 3,140 \\
\hline
\end{tabular}

The highest average value was determined for the variable scale The occupational safety and health system in the organization $(M=114,42)$, which reflects the function and activities of occupational safety and health for workers.

Scattering diagrams are used to investigate the relationship between variables, most often before calculating correlations. They approximately portray the strength of correlations among variables. A strong correlation is indicated by the accumulation of points around an imaginary line [20].

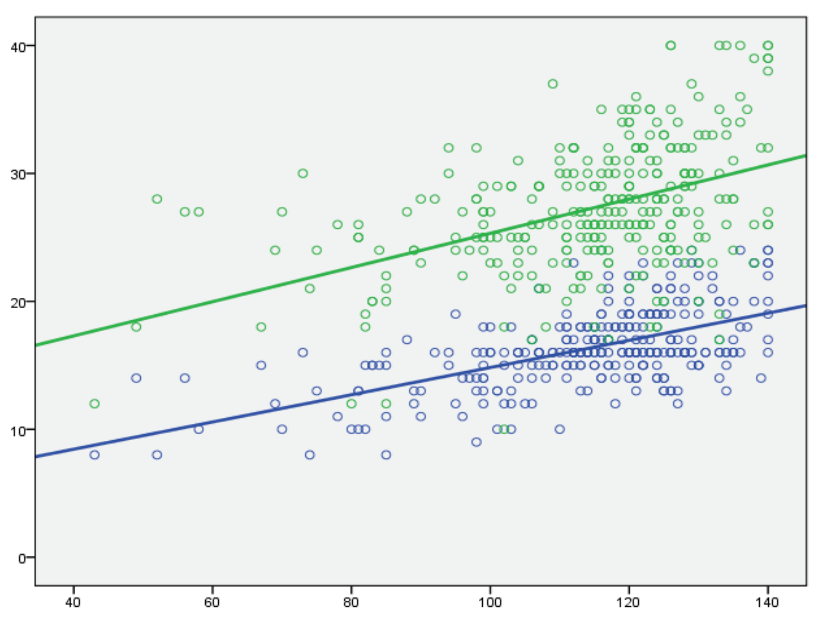

Figure 4 Positive interconnection of variables The occupational safety and health system in the organization ( $x$-axis) and dependent variables ( $y$-axis) shown by the scattering diagram

Fig. 4 shows that the increase on the scale of The occupational safety and health system in the organization is followed by the rise on the scale of dependent variables (the blue line increases on the scale of The state (performance) of occupational health and safety in the organization, and the green line increases on the scale of Injuries at work in the organization). Correlation analysis
(Spearman's rho) was used to determine the statistical significance of the relationship of the research variables. The results of the correlation analysis (Tab. 4) showed that there is a statistically significant correlation between variables The occupational safety and health system in the organization and other dependent variables at the significance level of $<0,01$. Workers-respondents who rated the elements of the occupational safety and health system higher on the scale of The occupational safety and health system in the organization statistically significantly assessed the causes of work injury in the organization and evaluated the state (performance) of occupational health and safety in organization as good.

Correlation determines the relationship between variables, where the correlation coefficient determines the strength of that connection. Due to the previously stated that data are not subject to normal distribution, Spirman's correlation (coefficient rho) was used. Various authors use different interpretations of the correlation coefficient: according to $[20,21]$ from 0,1 to 0,29 poor, from 0,30 to 0,49 medium and from 0,5 to 1 strong; according to $[22,23]$ from 0,2 to 0,4 poor, from 0,4 to 0,7 significant and from 0,7 to 1 a high or a very high correlation. Correlations of individual variations of the group Injuries at work in the organization and The state (performance) of occupational safety and health in the organization are shown in Tabs. 5 and 6.

The correlation matrix in Tab. 4 shows a strong positive correlation between the variables The occupational safety and health in the organization and The state (performance) occupational safety and health in the organization according to $[20,21]$, i.e. significant positive correlation of variables The occupational safety and health system in the organization with variables Injuries at work in the organization and The state (performance) of occupational safety and health in the organization according to $[22,23]$.

Table 4 Correlation matrix of the relationship of variables

\begin{tabular}{|c|c|c|c|c|c|}
\hline \multicolumn{3}{|c|}{ Production system } & 1. & 2. & 3. \\
\hline \multirow{6}{*}{ 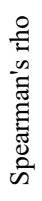 } & \multirow{2}{*}{ 1. The occupational safety and health system in the organization } & Corr. Coeff. & 1,000 & $0,411^{* *}$ & $0,510^{* *}$ \\
\hline & & Sig. (2-tail.) & & 0,000 & 0,000 \\
\hline & \multirow{2}{*}{ 2. Injuries at work in the organization } & Corr. Coeff. & $0,411^{* *}$ & 1,000 & $0,162^{* *}$ \\
\hline & & Sig. (2-tail.) & 0,000 & . & 0,005 \\
\hline & \multirow{2}{*}{ 3. The state (performance) of occupational safety and health in the organization } & Corr. Coeff. & $0,510^{* *}$ & $0,162^{* *}$ & 1,000 \\
\hline & & Sig. (2-tail.) & 0,000 & 0,005 &. \\
\hline
\end{tabular}

Correlations of variables Injuries at work in the organization are shown in Tab. 5. A strong positive correlation i.e. significant positive correlation was established for all variables, with the exception of variable Workers are trained to provide first aid in the event of an injury at work, with a medium i.e. poor correlation. The highest correlation was determined for the variable Injuries at work are the result of failure (malfunction) of the means of work, i.e. evaluating the causes of injuries by workers, pointing to poor functioning of the occupational safety system in the part relating to the management of inspection controls. Injuries at work variable is the result of failure 
(malfunction) of the means of work explains 49,84\% (0,706 $\times 0,706)$ variances in the workers' responses to the scale of Injuries at work in the organization. Deviation of the strength of correlation of variables Workers are trained to provide first aid in the event of an injury at work in relation to other variables indicates that the chosen first-aid training should be reviewed and, if necessary, optimized.

Table 5 Correlation matrix of variables Injuries at work in the organization

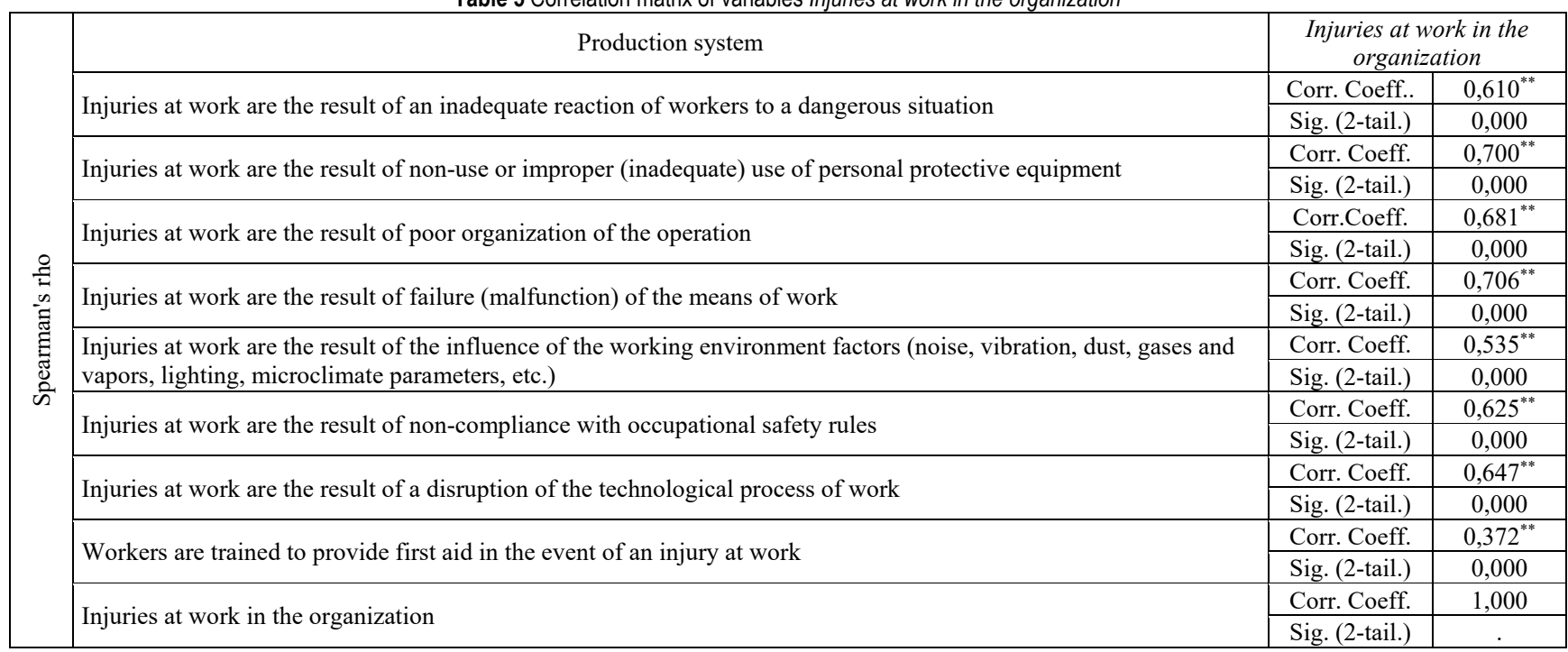

Table 6 Correlation matrix of the relationship of variable The state (performance) of occupational safety and health in the organization [1]

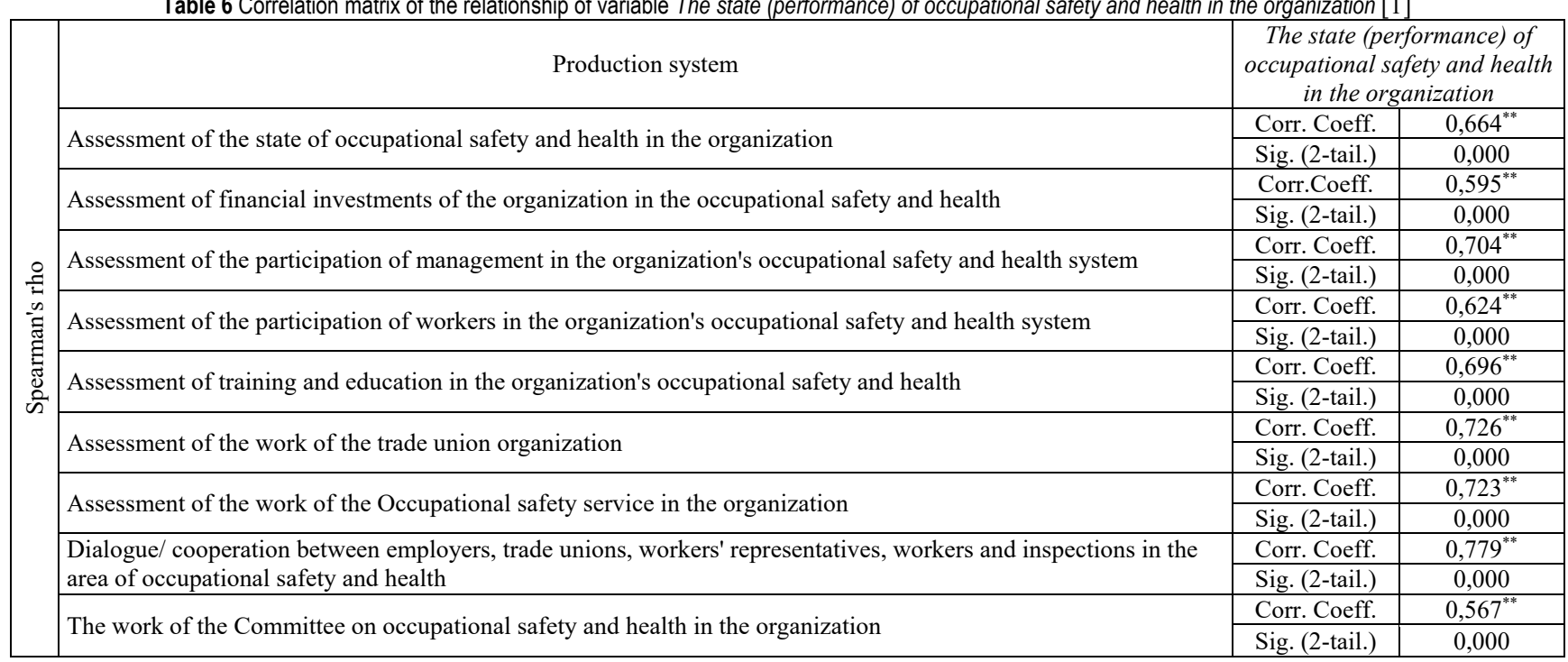

All measurement scale variables The state (performance) of occupational health and safety in the organization shown in Tab. 6 have a strong positive, ie significant and high positive correlation. Variable Dialogue/ cooperation between employers, trade unions, workers' representatives, workers and inspectors in the area of occupational safety and health with the strongest correlation explains $60.68 \%(0.779 \times 0.779)$ variances in workers' responses to the scale of The state (performance) of occupational safety and health in the organization. The workers' attitude is that for the effective functioning of the system of occupational safety and health, the active engagement of all stakeholders in the occupational safety system in the process of its optimization based on mutual dialogue is important.

\section{CONCLUSION}

In the survey research presented here the assessments made by the respondents - workers about the cause of injury at work and the state of occupational safety were selected as performance indicators of the occupational safety and health system in the production system "ArcelorMittal" Prijedor. The correlation established between a group of independent variables The occupational safety and health system in the organization and groups of dependent variables Injuries at work in the organization and The state (performance) of occupational safety and health in the organization indicate the connection of the existing occupational safety system applied according to the established model (Fig. 1) and indicators of occupational safety in the form of injuries at work and selected performance. Strong correlation determined between the individual variables of the scale The state (performance) of occupational safety and health 
in the organization confirms that higher rating of any selected indicator of occupational safety state is followed by higher evaluation of the overall occupational safety state in the production system. The presented research is a simple model for determining the connection between the established occupational safety system in the production system and the selected indicators of occupational safety state.

Monitoring of injury indicators (frequency and severity) by a linear trend model is an easy way to determine the appearance of a disturbed condition of the working environment in the form of a rising trend, or an increase in the number of injuries and other indicators. In this case, it is necessary to optimize the occupational safety system by designing measures that will reduce the number of injuries and their indicators and improve the entire occupational safety system in the production system.

The conducted research shows the way of monitoring the state of occupational safety, managing the occupational health and safety system in the production system, as well as revealing weak points towards which the optimization measures should be directed. The presented method enables workers to actively participate in the process of improving the occupational safety system. Workers can express their attitudes on the current state of occupational safety, and after the analysis, possible shortcomings and correction measures are identified.

Companies should show an open approach and flexibility in adopting new concepts in the occupational health and safety system. The research should also be extended to companies from other industries in order to determine the characteristics of the management of occupational safety and health systems in such companies. This model should be used to create measures to improve the existing occupational safety system in the production system using these or some other indicators.

\section{REFERENCES}

[1] Vranješ, B. \& Todić, M. (2019). A Comparative Analysis of the Occupational Safety and Health System in Production System. Technique, Journal of the Association of Engineers and Technicians of Serbia, 3, 461-468. https://doi.org/10.5937/tehnika1903461V

[2] Knegtering, B. (2002). Safety life cycle management in the process industries: the development of a qualitative safetyrelated information analysis technique. Eindhoven: Technische Universiteit, Eindhoven.

[3] Baldauf, P. E. J. (2010). Measuring Safety Performance: What are KPIs? EHS Journal-Practical Solutions for Environmental. Health and Safety Professionals. http://ehsjournal.org/http:/ehsjournal.org/janbaldauf/measuring-safety-performance-kpis/2010/

[4] Vranješ, B. \& Anđelković, B. (2019). Analysis of the performance of occupational health and safety in the production business system. IOP Publishing, IOP Conf.Series: Materials Science and Engineering 477 012038. https://doi.org/10.1088/1757-899X/477/1/012038

[5] Kolonja, Lj. (2016). Business Intelligence System for Occupational Safety Management at the Mining Industry. Doctoral dissertation, University of Belgrade, Faculty of Mining and Geology, Belgrade.

[6] Adzah, G., Asamoah, R. K., Yamoah, S. A., \& Temeng, V. A. (2018). Aspects of Occupational Safety Practices and
Injury Analysis: A Case Study. Journal of Chemical Engineering \& Process Technology, 9(1).

https://doi.org/10.4172/2157-7048.1000369

[7] Zvetsloot, G., Leka, S., \& Kines, P. (2017). Vision Zero: from accident prevention to the promotion of health, safety and wellbeing at work. Journal Policy and Practice in Health and Safety, 15(2), 88-100. https://doi.org/10.1080/14773996.2017.1308701

[8] International Council of Minnig \& Metals (2012). Overview of leading indicators for occupational health and safety in mining. London, United Kingdom.

[9] Haas, J. E., Ryan, M., \& Willmer, R. D. (2018). An Examination of Mining Companies' Online Health and Safety Policies: Implications for Improving Risk Management. Journal of Safety, Health and Environmental Research, 14(1), 337-347.

[10] Elgstrand, K. \& Vingård, E. (2013). Occupational Safety and Health in Mining. Anthology on the situation in 16 mining countries, 47(2). University of Gothenburg, NR 2013.

[11] Ural, S., \& Demirkol, S. (2008). Evalution of Occupational safety and health in surface mines. Safety Science, 46(6), 1016-1024. https://doi.org/10.1016/j.ssci.2007.11.010

[12] Zhou, L., Cao, Q., Yu, K., Wang, L. \& Wang, H. (2018). Research on Occupational Safety, Health Management and Risk Control Technology in Coal Mines. International Journal Environmental Research and Public Health, 15, 868. https://doi.org/10.3390/ijerph15050868

[13] Venkataraman, N. (2008). Safety Performance Factor. International Journal of Occupational Safety and Ergonomics (JOSE), 14(3), 327-331. https://doi.org/10.1080/10803548.2008.11076772

[14] Živković, S. \& Pavlović, D. (2014).The comparative analysis of the number of occupational injuries in Serbia, Croatia and Slovenia in 2012. Facta Universitatis, Series: Working and Living Environmental Protection, 11(1), 53 64.

[15] Stranks, J. (2011). Health and safety at Work-Key Terms. Routledge Taylor \& Francis Group, London and New York

[16] Krstić, I. (2010). Models for systemic analysis of technological systems, Doctoral dissertation, Faculty of Occupational Safety in Niš, Niš.

[17] Perttula, P. (2017, December 15). Zero accident vision. Finnish Institute of Occupational Health, OSHwiki, Networking knowledge. https://oshwiki.eu/wiki/

[18] Ryan, D. (2009). Safety Management Perception Survey Process. Journal of the American Society of Safety Professionals, Professional Safety, 18-27.

[19] Aranđelović, I., Mitrović, Z., \& Stojanović, V. (2011). Probability and Statistics, Belgrade Institute for Textbooks, Belgrade.

[20] Pallant, J. (2007). SPSS Survival Manual: A Step by Step Guide to Data Analysis Using SPSS for Windows (Version 15), Allen \& Unwin.

[21] Cohen, J. W. (1988). Statistical power analysis for the behavioral sciences $\left(2^{\text {nd }}\right.$ edn.) Hillsdale, NJ: Lawrence Erlbaum Associates.

[22] Petz, B. (1997). Basic statistical methods for nonmathematicians, Edition Waterfalll, Zagreb.

[23] Ratner, B. (2009). The correlation coefficient: Its values range between $+1 /-1$, or do they? Journal of Targeting, Measurement and Analysis for Marketing, 17(2), 139-142. https://doi.org/10.1057/jt.2009.5 


\section{Contact information:}

Biljana VRANJEŠ, MSc, Senior assistant

(Corresponding author)

University of Banja Luka, Faculty of Mechanical Engineering,

Stepe Stepanovića 71, 78000 Banja Luka, Bosnia and Hercegovina

E-mail: biljana.vranjes@mf.unibl.org

Mladen TODIĆ, PhD, Professor

University of Banja Luka, Faculty of Mechanical Engineering,

Stepe Stepanovića 71, 78000 Banja Luka, Bosnia and Hercegovina

E-mail:mladen.todic@mf.unibl.org

Valentina GOLUBOVIĆ-BUGARSKI, PhD, Professor

University of Banja Luka, Faculty of Mechanical Engineering,

Stepe Stepanovića 71, 78000 Banja Luka, Bosnia and Hercegovina

E-mail: valentina.golubovic-bugarski@mf.unibl.org 